\title{
Dietary $\omega-3$ Polyunsaturated Fatty Acids Inhibit Phosphoinositide Formation and Chemotaxis in Neutrophils
}

\author{
Richard I. Sperling, * A Anthony I. Benincaso," Christopher T. Knoell," John K. Larkin, \\ K. Frank Austen, ${ }^{* *}$ and Dwight R. Robinson * \\ ${ }^{*}$ Department of Medicine, Harvard Medical School, Boston, MA 02115; ${ }^{\ddagger}$ Department of Rheumatology and Immunology, Brigham and \\ Women's Hospital, Boston, MA 02115; and §Arthritis Unit, Massachusetts General Hospital, Boston, MA 02114
}

\begin{abstract}
Earlier studies demonstrated that dietary $\omega-3$ polyunsaturated fatty acid (PUFA) supplementation attenuates the chemotactic response of neutrophils and the generation of leukotriene (LT) $B_{4}$ by neutrophils stimulated with calcium ionophore; however, the mechanisms and relationship of these effects were not examined. Neutrophils and monocytes from eight healthy individuals were examined before and after 3 and 10 wk of dietary supplementation with $20 \mathrm{~g}$ SuperEPA daily, which provides 9.4 g eicosapentaenoic acid (EPA) and $5 \mathrm{~g}$ docosahexaenoic acid. The maximal neutrophil chemotactic response to $\mathbf{L T B}_{4}$, assessed in Boyden microchambers, decreased by $69 \%$ after 3 wk and by $93 \%$ after 10 wk from prediet values. The formation of $\left[{ }^{3} \mathrm{H}\right]$ inositol tris-phosphate $\left(\mathrm{IP}_{3}\right)$ by $\left[{ }^{3} \mathrm{H}\right]$ inositol-labeled neutrophils stimulated by $\mathrm{LTB}_{4}$ decreased by $71 \%$ after 3 wk $\left(0.033 \pm 0.013 \%\left[{ }^{3} \mathrm{H}\right]\right.$ release, mean \pm SEM) and by $90 \%$ after 10 wk $(0.011 \pm 0.011 \%)$ from prediet values $(0.114 \pm 0.030 \%)$ as quantitated by $\beta$-scintillation counting after resolution on HPLC. LTB $_{4}$-stimulated neutrophil chemotaxis and $\mathrm{IP}_{3}$ formation correlated significantly $(P<0.0001)$; each response correlated closely and negatively with the EPA content of the neutrophil phosphatidylinositol (PI) pool $(P=0.0003$ and $P$ $=0.0005$, respectively). Neither the affinities and densities of the high and low affinity $\mathrm{LTB}_{4}$ receptors on neutrophils nor LTB $_{4}$-mediated diglyceride formation changed appreciably during the study. Similar results were observed in neutrophils activated with platelet-activating factor (PAF). The summed formation of $\mathrm{LTB}_{4}$ plus $\mathrm{LTB}_{5}$ was selectively inhibited in calcium ionophore-stimulated neutrophils and was also inhibited in zymosan-stimulated neutrophils. The inhibition of the summed formation of $\mathrm{LTB}_{4}$ plus $\mathrm{LTB}_{5}$ in calcium ionophorestimulated neutrophils and in zymosan-stimulated neutrophils did not correlate significantly with the EPA content of the PI pool. The data indicate that dietary $\omega-3$ PUFA supplementation inhibits the autoamplification of the neutrophil inflammatory response by decreasing $\mathrm{LTB}_{4}$ formation through the inactivation of the LTA epoxide hydrolase and independently by inhibiting LTB $_{4}$ - (and PAF) stimulated chemotaxis by attenuating the formation of $\mathrm{IP}_{3}$ by the PI-selective phospholipase C. This is the initial demonstration that dietary $\omega-3$ PUFA
\end{abstract}

Address reprint requests to Richard I. Sperling, M. D., Department of Rheumatology and Immunology, Brigham and Women's Hospital, 250 Longwood Avenue, Room 618, Boston, MA 02115.

Received for publication 27 May 1992 and in revised form $10 \mathrm{Au}$ gust 1992.

J. Clin. Invest.

(c) The American Society for Clinical Investigation, Inc.

$0021-9738 / 93 / 02 / 0651 / 10 \$ 2.00$

Volume 91, February 1993, 651-660 supplementation can suppress signal transduction at the level of the PI-specific phospholipase $\mathrm{C}$ in humans. (J. Clin. Invest. 1993. 91:651-660.) Key words: fish oil • inositol phosphates • monocytes $\bullet$ platelet-activating factor $\bullet$ phospholipids

\section{Introduction}

AA $(20: 4, \omega-6)$, the major substrate for both the cyclooxygenase and 5-lipoxygenase pathways in humans on a typical Western diet, is derived from $\omega-6$ polyunsaturated fatty acids (PUFA) ${ }^{1}$ of land-based plants and animals. Eicosapentaenoic acid (EPA, 20:5, $\omega-3$ ) and docosahexaenoic acid (DHA; 22:6, $\omega-3)$, found primarily in the form of esterified triglycerides, are each major fatty acids in marine organisms. Dietary marine fish oils rich in $\omega-3$ PUFA have an antiinflammatory effect in murine models of lupus $(1,2)$ and RA (3). Several small studies of the effects of dietary $\omega-3$ PUFA supplementation in patients with RA have each demonstrated modest clinical benefit (4-8). In healthy individuals dietary supplementation with $\omega-3$ PUFA inhibits leukotriene (LT) $\mathbf{B}_{\mathbf{4}}$ formation by human neutrophils activated ex vivo with calcium ionophore A23187 (9). However, its effects on $\mathrm{LTB}_{4}$ formation in receptor-stimulated neutrophils are unknown. Dietary supplementation with $\omega-3$ PUFA in healthy volunteers inhibits neutrophil chemotaxis to a range of concentrations of $\mathrm{LTB}_{4}$ (9) and suppresses the $\mathrm{LTB}_{\mathbf{4}}$-mediated enhancement of adherence to endothelial cell monolayers $(9,10)$. Both functional responses of the neutrophils returned nearly to baseline levels $6 \mathrm{wk}$ after the dietary fish oil was discontinued, further supporting a causal relationship. These results were subsequently confirmed by others ( 11 , 12 ). No changes in neutrophil membrane fluidity were detected by fluorescence polarization in cells doped with the fluorescent probe, 1,6-diphenyl-1,3,5-hexatriene (9). The mechanism(s) by which dietary $\omega-3$ PUFA supplementation modulates transmembrane stimulation of neutrophils by chemotactic ligands were not addressed in previous studies. Early events in the signal transduction of the neutrophil chemotactic ligands $\mathrm{LTB}_{4}$, platelet-activating factor (PAF), and FMLP are believed to involve the activation of a G-protein-associated, phosphatidylinositol (PI)-selective phospholipase C $(13,14)$. The activated phospholipase $\mathrm{C}$ hydrolyzes PI-4,5-bis-phosphate, resulting in the formation of inositol-1,4,5-tris-phos-

1. Abbreviations used in this paper: alkylacylPC, 1-O-alkyl-2-acyl-snglycero-3-phosphocholine; alkenlacylPE, 1-O-alk-1'-enyl-2-acyl-snglycero-3-phosphoethanolamine; DHA, docosahexaenoic acid; EPA, eicosapentaenoic acid; 5-HEPE, $5 S$-hydroxy-eicosapentaenoic acid; 5HETE, $5 S$-hydroxy-eicosatetraenoic acid; hpf, high power field; $\mathrm{IP}_{1}$, inositol phosphate; $\mathrm{IP}_{2}$, inositol bis-phosphate; $\mathrm{IP}_{3}, 1,4,5$-inositol trisphosphate; PI, phosphatidylinositol; PAF, platelet-activating factor; PUFA, polyunsaturated fatty acid(s); RP-HPLC, reverse-phase HPLC; THA, Tyrode's-Hepes-albumin buffer. 
phate $\left(\mathrm{IP}_{3}\right)$ and diacylglycerols. $\mathrm{IP}_{3}$ binds to specific receptors on the endoplasmic reticulum, resulting in the release of intracellular stores of calcium and activation of phospholipases $A_{2}$ and D (15). The diacylglycerols, in conjunction with the increased cytoplasmic calcium ion concentration, activate protein kinase $C$ and lead to activation of other specific cellular pathways (16).

In this study, we demonstrate that dietary supplementation with $\omega$-3 PUFA in healthy human volunteers leads to the inhibition of chemotaxin-mediated phosphoinositide formation in neutrophils in parallel with inhibition of chemotaxis without affecting appreciably neutrophil chemotaxin receptor density or affinity or diglyceride formation. The suppression of receptor-mediated stimulation of LTB generation is attributed to the inactivation of the LTA epoxide hydrolase by the EPA-derived intermediate, LTA $_{5}$. Unlike chemotaxis, this suppression is not significantly correlated either with the EPA content of PI or with the suppression of the second messenger, $\mathrm{IP}_{3}$. These dual effects of dietary supplementation with $\omega-3$ PUFA could attenuate substantially the amplification of the neutrophil inflammatory response mediated by $\mathrm{LTB}_{4}$. Furthermore, the profound inhibition of ligand-stimulated $\mathrm{IP}_{3}$ formation and chemotaxis demonstrates a novel action of dietary $\omega-3$ PUFA on PI pathway-mediated signal transduction.

\section{Methods}

Subjects and study design. Informed consent was obtained from eight healthy volunteers, three men and five women aged $43 \pm 11$ y (mean \pm SD, range 25-59 y); the volunteers were chosen to be demographically representative of the population of patients with RA entering clinical trials at the Robert B. Brigham Arthritis Center of the Brigham and Women's Hospital. The subjects supplemented their usual diet with $20 \mathrm{~g}$ SuperEPA (Pharmacaps, Elizabeth, NJ) daily, providing $9.4 \mathrm{~g} \mathrm{EPA}, 5 \mathrm{~g} \mathrm{DHA}$, and $180 \mathrm{kcal}$ daily, for $10 \mathrm{wk}$, beginning $4 \mathrm{wk}$ after they entered the study. During the study, seven of the volunteers experienced mild gastrointestinal symptoms, which included eructation, diarrhea, and occasional mild steatorrhea; none of the volunteers withdrew from the study because of these symptoms. Pill counts and analyses of the fatty acid composition of leukocyte membranes indicated compliance with the prescribed regimen. A complete blood count with platelet count was obtained on entry to the study and after 10 wk of dietary supplementation with $\omega-3$ PUFA. One unit of venous blood was obtained at three time points during the course of the study for the analysis of selected neutrophil and monocyte cellular functions: on entry (4 wk before starting dietary supplementation with $\omega-3$ PUFA) and after $3 \mathrm{wk}$ and $10 \mathrm{wk}$ of dietary supplementation was begun. Chemotaxis, receptor affinity and density, and inositol phosphate and diglyceride formation by $\mathrm{LTB}_{4}$ and PAF-stimulated neutrophils, and the formation of 5-lipoxygenase pathway products by calcium ionophore- and zymosan-stimulated neutrophils were evaluated. Calcium ionophore and PAF-stimulated 5-lipoxygenase pathway product generation and PAF-stimulated inositol phosphate and diglyceride formation were investigated in monocytes.

Activation of neutrophils and monocytes and quantitation of 5-lipoxygenase pathway products. Neutrophils and monocytes were isolated from the venous blood by dextran sedimentation and Ficoll-Hypaque discontinuous gradient centrifugation $(9,17)$. Neutrophils were purified further from contaminating red cells by hypotonic lysis. Monocytes were isolated further by adhesion on silanized glass culture dishes, as previously described (18). Before investigation, the monocyte monolayers were cultured overnight in RPMI 1640 (Gibco Laboratories, Grand Island, NY) with $100 \mathrm{U} / \mathrm{ml}$ penicillin, $100 \mu \mathrm{g} / \mathrm{ml}$ streptomycin, $2 \mathrm{mM}$ L-glutamine, and $5 \%$ heat-inactivated autologous serum.

5-Lipoxygenase products were quantitated by reverse-phase HPLC (RP-HPLC) in parallel, duplicate portions of neutrophil suspensions and monocyte monolayers that had been preincubated in Tyrode's buffer with $30 \mathrm{mM}$ Hepes, $\mathrm{pH} 7.4$, and $1 \mathrm{mg} / \mathrm{ml}$ bovine serum albumin (THA) for $5 \mathrm{~min}$ at $37^{\circ} \mathrm{C}$ before activation. Albumin in the incubation buffer minimized the underestimation of $5 S$-hydroxy-eicosatetraenoic acid ( 5 -HETE) formation by decreasing the esterification into cellular phospholipids of the 5-HETE that was generated (19). Duplicate portions of $4 \times 10^{6}$ neutrophils suspended in $400 \mu$ l THA were activated by the addition of $400 \mu \mathrm{l}$ of buffer alone or containing calcium ionophore A23187 at a final concentration of $10 \mu \mathrm{M}$ or $8 \times 10^{8}$ boiled zymosan particles (gift of Dr. Joyce Czop), and the samples were incubated at $37^{\circ} \mathrm{C}$ for $15 \mathrm{~min}$. The reactions were terminated by rapid cooling to $0^{\circ} \mathrm{C}$. After centrifugation of the samples at $10,000 \mathrm{~g}$ for 1 min at $0^{\circ} \mathrm{C}$, the supernatants were harvested and the cell pellets were extracted with $800 \mu$ l of methanol (9). Both fractions were stored under a nitrogen atmosphere at $-70^{\circ} \mathrm{C}$ until analyzed. The monocyte monolayers were preincubated in THA at $37^{\circ} \mathrm{C}$ for $15 \mathrm{~min}$, the supernatants were discarded, and duplicate monolayers were incubated for 15 min with either $1 \mathrm{ml}$ of THA alone or containing $10 \mu \mathrm{M}$ calcium ionophore A23187 or $1 \mu \mathrm{M}$ PAF (Bachem Bioscience, Inc., Torrence, CA). At the end of the incubation period, the fluid over the monocyte monolayers was decanted and retained, the monocyte monolayers were extracted with $1 \mathrm{ml}$ of methanol, and both fractions were stored as described above.

For analysis on RP-HPLC, equal portions of supernatants and cell extracts were combined and the methanol in the samples was diluted by the addition of $250 \mu \mathrm{l}$ of distilled, deionized water. Samples were injected onto an Ultrasphere ODS $5 \mu \mathrm{m}$ column $(4.6 \times 150 \mathrm{~mm})$ (Beckman Instruments, Inc., Berkeley, CA), preequilibrated with $100 \%$ solvent $\mathrm{A}(0.1 \%$ [ $\mathrm{vol} / \mathrm{vol}]$ aqueous acetic acid/ammonium acetate, pH 5.6:methanol:acetonitrile, 70:15:15 [vol/vol]). The column was eluted at a flow rate of $1 \mathrm{ml} / \mathrm{min}$ beginning with $100 \%$ solvent $A$ for $3 \mathrm{~min}$, followed by a step gradient to $71.4 \%$ solvent $\mathrm{A}$ and $28.6 \%$ $85: 15$ ( vol/vol) methanol:acetonitrile (solvent B), with a 15-min linear gradient to $50 \%$ solvent $B$, followed by a 15 -min linear gradient to $68.4 \%$ solvent $B$, and then a 12 -min linear gradient to $100 \%$ solvent $B$. The column was recycled by washing with $100 \%$ solvent B and then reequilibrated with $100 \%$ solvent $A$. Product elution was quantitated by integrated optical density, continuously monitored at $269 \mathrm{~nm}$ (for LTs) and $234 \mathrm{~nm}$ (for HETEs). The column was calibrated with known quantities of synthetic standards, and the quantities reported are corrected for recovery. Retention times were as follows (mean $\pm \mathrm{SD}$ ): 20-carboxy-LTB ${ }_{4}, 10.81 \pm 1.00 \mathrm{~min} ; 20$-hydroxy-LTB $\mathrm{L}_{5}$, $14.75 \pm 0.84 \mathrm{~min} ; 20$-hydroxy-LTB, $17.91 \pm 0.78 \mathrm{~min} ; 5 S, 12 R-6$ trans- $\mathrm{LTB}_{5}, 24.30 \pm 0.59 \mathrm{~min} ; 5 S, 12 S-6$-trans $-\mathrm{LTB}_{5}, 24.96 \pm 0.61 \mathrm{~min}$; $\mathrm{LTB}_{5}, 26.32 \pm 0.47 \mathrm{~min} ; 5 S, 12 R-6-$ trans $-\mathrm{LTB}_{4}, 28.00 \pm 0.44 \mathrm{~min}$; $5 S, 12 S$-6-trans-LTB ${ }_{4}, 29.68 \pm 0.47 \mathrm{~min} ; \mathrm{LTB}_{4}, 31.15 \pm 0.80 \mathrm{~min} ; 5 S$ hydroxy-eicosapentaenoic acid (5-HEPE), 45.04 $\pm 0.81 \mathrm{~min}$; and 5HETE, $50.49 \pm 2.31 \mathrm{~min}$. The recoveries (mean $\pm \mathrm{SD}$ ) of $\left[{ }^{3} \mathrm{H}\right] \mathrm{LTB}_{4}$ and $\left[{ }^{3} \mathrm{H}\right] 5$-HETE from the HPLC column were $75.5 \pm 7.1$ and $55.4 \pm 2.3 \%$, respectively. Synthetic $\mathrm{LTB}_{4}$ and 6-trans- $\mathrm{LTB}_{4}$ diastereoisomers were prepared as described (20); synthetic 5-HETE, 20-hydroxy-LTB , $_{4}$ and 20-carboxy-LTB ${ }_{4}$ were obtained from Cayman Chemical Co. Inc. (Ann Arbor, MI). The generation of 5-lipoxygenase pathway products is reported in $\mathrm{ng} / 10^{6}$ cells, as the mean $\pm \mathrm{SEM}$, corrected for recovery. The formation of $\mathrm{LTB}_{4}$ and $\mathrm{LTB}_{5}$ was confirmed by RIA of the fractional eluates (9) using synthetic standards, as only modest quantities of $\mathrm{LTB}_{\mathbf{s}}$ were formed. Quantitation of these products by integrated optical density and RIA yielded similar results.

Chemotaxis assay. The chemotactic responses of neutrophils and mononuclear cells to concentrations $\left(10^{-9}-10^{-6} \mathrm{M}\right)$ of synthetic $\mathrm{LTB}_{4}$ and PAF were assessed in Boyden microchambers by determining the number of cells migrating the same distance as the leading edge in control samples; a nitrocellulose membrane with a $5-\mu \mathrm{m}$ pore size was used $(9,21,22)$. The experiments were performed in duplicate with interassay and intraassay coefficients of variation of $<35$ and $<25 \%$, respectively (9). Results are expressed as the average number of neutrophils per 5 high power fields (hpf) after correction for background migration; $10 \mathrm{hpf}$ were counted per sample. 
Measurement of $L T B_{4}$ and $P A F$ receptor density and affinity. The density and affinity of the neutrophil $\mathrm{LTB}_{4}$ and PAF receptors were determined by the displacement by unlabeled ligand of the binding of labeled ligand (23). Duplicate portions of $2.5 \times 10^{6}$ neutrophils were incubated with $\sim 1.5 \times 10^{-10} \mathrm{M}\left[{ }^{3} \mathrm{H}\right] \mathrm{LTB}_{4}$ (specific activity $174 \mathrm{Ci}$ / mmol; NEN-Dupont, Boston, MA) or $7.2 \times 10^{-10} \mathrm{M}\left[{ }^{3} \mathrm{H}\right] \mathrm{PAF}$ (specific activity $80 \mathrm{Ci} / \mathrm{mmol}$; NEN-Dupont $)$ plus concentrations $\left(0-10^{-6}\right.$ $\mathrm{M})$ of unlabeled ligand at $0^{\circ} \mathrm{C}$. The neutrophils were separated from the unbound ligand by rapid filtration on glass fiber filters under vacuum; the bound counts, retained on the filter, were eluted in $10 \mathrm{ml}$ of Aquasol and counted by $\beta$-scintillation. Receptor density and affinity were determined by computer modeling with the Ligand Program for the Macintosh Computer (National Institutes of Health, Bethesda, MD). This method minimized the number of cells needed to assay receptor density and affinity.

Quantitation of phosphoinositide formation. The formation of phosphoinositides was quantitated in myo- $\left[{ }^{3} \mathrm{H}\right]$ inositol-labeled neutrophils and monocytes by an HPLC assay. Neutrophils and monocytes were labeled by incubation with myo- $\left[{ }^{3} \mathrm{H}\right]$ inositol (Amersham Corp., Arlington Heights, IL) by a modification of the technique of DiVirgilio et al. (24). Briefly, the labeling medium was inositol-free RPMI 1640 (Gibco Laboratories) with $100 \mathrm{U} / \mathrm{ml}$ penicillin, $100 \mu \mathrm{g} /$ $\mathrm{ml}$ streptomycin, $2 \mathrm{mM}$ L-glutamine, $25 \mu \mathrm{Ci} / \mathrm{ml}$ myo- $\left[{ }^{3} \mathrm{H}\right]$ inositol, and $5 \%$ heat-inactivated autologous serum. Neutrophils $\left(75 \times 10^{6}\right)$ were incubated in $5 \mathrm{ml}$ of labeling medium at $37^{\circ} \mathrm{C}$ for $2 \mathrm{~h}$. The labeled cells were washed three times in HBSS without divalent cations with 1 $\mathrm{mg} / \mathrm{ml} \mathrm{BSA}$, resuspended in THA, and prewarmed at $37^{\circ} \mathrm{C}$ for $5 \mathrm{~min}$ before being activated. Samples of neutrophils $\left(10^{7}\right.$ cells $\left./ 150 \mu \mathrm{l}\right)$ were activated in duplicate by the addition of $\mathrm{LTB}_{4}$ or PAF (final concentration $1 \mu \mathrm{M}$ ) or of THA buffer alone for $15 \mathrm{~s}$. The monocyte monolayers were cultured overnight in labeling medium, washed three times with HBSS without divalent cations with $1 \mathrm{mg} / \mathrm{ml} \mathrm{BSA}$, preincubated in THA for $15 \mathrm{~min}$, and then activated in duplicate with $1 \mu \mathrm{M}$ PAF or THA buffer alone for $15 \mathrm{~s}$. The reactions of neutrophils and monocytes were terminated, and inositol phosphates were extracted by the method of Seiss (25). The extracts were evaporated to dryness under reduced pressure and redissolved in $200 \mu \mathrm{l}$ of distilled water; $2 \times 10^{-7} \mathrm{~mol}$ of AMP, ADP, and ATP were added to each sample as retention time standards. The samples were injected into a Partisil SAX10 column $(250 \times 4.6 \mathrm{~mm})$ with a $10-\mu \mathrm{m}$ pore size (Whatman Labsales, Hillsboro, $\mathrm{OR}$ ) and eluted with increasing concentrations of ammonium formate/phosphoric acid, $\mathrm{pH} \mathrm{3.7,} \mathrm{to} 2 \mathrm{M}$, using a modification of the program of Irvine et al. (26). The elution of the adenosine phosphate standards was monitored by on-line ultraviolet absorption at $257 \mathrm{~nm}$, and the $\left[{ }^{3} \mathrm{H}\right]$ inositol phosphates eluted were quantitated by on-line HPLC $\beta$-scintillation counting using a scintillation counter (Radiomatic $\beta$-One; Packard Instruments Co., Inc., Canberra Industries, Meriden, CT). The retention times (mean $\pm \mathrm{SD})$ in this system were as follows: AMP, $16.5 \pm 1.7 \mathrm{~min}$; $\mathrm{IP}_{1}, 17.3 \pm 1.8 \mathrm{~min}$; ADP, $22.6 \pm 2.5 \mathrm{~min}$; $\mathrm{IP}_{2}, 25.0 \pm 2.7 \mathrm{~min}$; ATP, $32.5 \pm 3.2 \mathrm{~min}$; and $\mathrm{IP}_{3}, 38.2 \pm 3.6 \mathrm{~min}$. The recovery of $\left[{ }^{3} \mathrm{H}\right]$ standards (Amersham Corp.) were as follows: $\mathrm{IP}_{1}$, $76.8 \pm 1.3 \%$; $\mathrm{IP}_{2}, 76.1 \pm 1.7 \%$; and $\mathrm{IP}_{3}, 70.6 \pm 5.0 \%$; the quantum efficiency of measurement of the tritiated products by the on-line $\beta$-scintillation counter was $22 \%$.

Quantitation of 1,2-diacylglycerol formation. Diacylglycerols were quantitated by mass measurement by the method of Preiss et al. (27). Duplicate portions of $10^{7}$ neutrophils were suspended in $400 \mu \mathrm{l}$ THA containing $5 \mu \mathrm{g} / \mathrm{ml}$ cytochalasin B and were warmed at $37^{\circ} \mathrm{C}$ for 5 min. The duplicate portions were activated by the addition of $\mathrm{LTB}_{4}$ or PAF at a final concentration of $1 \mu \mathrm{M}$ in THA with $5 \mu \mathrm{g} / \mathrm{ml}$ cytochala$\sin B$ or by the addition of cytochalasin $B$ and buffer alone for control cells; all portions were incubated at $37^{\circ} \mathrm{C}$ for $2 \mathrm{~min}$. Duplicate monocyte monolayers were preincubated at $37^{\circ} \mathrm{C}$ with $1 \mathrm{ml}$ THA containing $5 \mu \mathrm{g} / \mathrm{ml}$ cytochalasin B for $5 \mathrm{~min}$. The overlying buffer was discarded, and duplicate monolayers were activated by the addition of $1 \mu \mathrm{M}$ PAF in THA with $5 \mu \mathrm{g} / \mathrm{ml}$ cytochalasin B or by the addition of buffer containing $5 \mu \mathrm{g} / \mathrm{ml}$ cytochalasin B alone for control cells, and the samples were incubated at $37^{\circ} \mathrm{C}$ for $2 \mathrm{~min}$. The reactions were terminated by the addition of an equal volume of methanol and rapid cooling on a dry ice/acetone slurry. Lipids were extracted by the method of Bligh and Dyer as modified by Preiss et al. (27), and 1,2-diacylglycerols were quantitated as $\left[{ }^{32} \mathrm{P}\right]$ phosphatidic acids after $\left[{ }^{32} \mathrm{P}\right] \mathrm{P}_{i}$-labeling with $\gamma$ ${ }^{32}$ P]ATP catalyzed by diacylglycerol kinase as described $(27)$. The incubation period and the concentration of cytochalasin $B$ were chosen to maximize the formation of 1,2-diacylglycerols.

Assays of the fatty acid composition of neutrophil and monocyte membranes. The fatty acid composition of the major phospholipid subclasses of neutrophil and monocyte cellular lipids were determined for each individual subject before and after 3 and 10 wk of dietary supplementation with $\omega-3$ PUFA to assess whether changes in the fatty acid composition of a particular phospholipid subclass(es) resulted in the observed functional changes. Cellular lipids were extracted by the Folch et al. procedure (28), and the phospholipids were separated into classes by straight-phase HPLC (29). To separate the ether-linked phospholipids, the phosphatidylethanolamine and phosphatidylcholine fractions were digested with phospholipase $\mathrm{C}$ from Bacillus cereus, and the resulting diradylglycerols were benzoylated to form the corresponding 3-benzoyl derivatives ( 30 ). The benzoyl-diradylglycerols were separated into the three major fractions, the alk-1-enyl and alkyl ethers and the diacyl fractions by straight-phase HPLC (30). The elution of the fractions was monitored and quantitated by benzoyl group absorbance at $230 \mathrm{~nm}$. The fatty acid composition of each phospholipid class and subclass was determined after acid-catalyzed transmethylation of each class and subclass, resolution of the fatty acids as the methyl ester derivatives by capillary gas chromatography, and quantitation by flame ionization (31).

Data analysis and statistics. The data were analyzed for overall statistical significance by a repeated measures design analysis of variance, followed by the Student's protected least-significant difference $t$ test to make individual pairwise comparisons on a Macintosh IIcx computer using the StatView 512+ statistics package (Abacus Concepts, Inc., Berkeley, CA). The formation of phosphoinositides and maximal chemotaxis were analyzed as above after a logarithmic transformation, and the dose-response data for chemotaxis were analyzed by a repeated-measures design multivariate analysis of variance with zero between and two within variables after logarithmic transformation, followed by means comparisons to make individual pairwise comparisons, on a Macintosh IIcx computer using the SuperANOVA statistics package (Abacus Concepts, Inc.). Correlations were made with the simple regression program in the StatView 512+ statistics package using the data from each time point for each individual. Data are presented as the mean \pm SEM unless otherwise stated.

\section{Results}

Neutrophil fatty acid composition. The fatty acid composition of the major neutrophil phospholipid classes and subclasses were modified considerably after 3 and $10 \mathrm{wk}$ of dietary supplementation with $\omega-3$ PUFA (Table I). The AA contents of the pools of 1,2-diacyl-sn-glycero-3-phosphocholine (diacylPC), 1-O-alkyl-2-acyl-sn-glycero-3-phosphocholine (alkylacylPC), 1,2-diacyl-sn-glycero-3-phosphoethanolamine (diacylPE), and 1-O-alk-1'-enyl-2-acyl-sn-glycero-3-phosphoethanolamine (alkenylacylPE) decreased significantly after 3 and 10 wk of dietary supplementation with $\omega-3$ PUFA, and there were no significant differences between the 3 and 10 wk time points. However, the AA content of the PI pool was not significantly affected. The EPA contents of each of these subclasses increased substantially after 3 and $10 \mathrm{wk}$ of dietary supplementation with $\omega$-3 PUFA above prediet values.

Neutrophil receptors for $L T B_{4}$ and PAF. The binding of $\mathrm{LTB}_{4}$ to neutrophils was fitted to a two-site model with the Ligand program. Neither the density nor the affinity of the high and low affinity receptors of neutrophils for $\mathrm{LTB}_{4}$ was signifi- 
Table I. Fatty Acid Composition of the Major Neutrophil Phospholipid Classes and Subclasses before and 3 and 10 wk after Dietary Supplementation with $\omega-3$ PUFA

\begin{tabular}{|c|c|c|c|}
\hline & Prediet & Week 3 & Week 10 \\
\hline \multicolumn{4}{|l|}{ Phosphatidylinositol } \\
\hline Arachidonic acid & $22.8 \pm 1.7$ & $25.9 \pm 1.0$ & $19.9 \pm 1.4$ \\
\hline Total $\omega-6$ PUFA & $37.7 \pm 2.2$ & $38.9 \pm 0.6$ & $32.4 \pm 1.6^{*}$ \\
\hline Eicosapentaenoic acid & $0.2 \pm 0.1$ & $1.7 \pm 0.2^{* *}$ & $1.9 \pm 0.2^{* *}$ \\
\hline Docosahexaenoic acid & $1.1 \pm 0.1$ & $0.2 \pm 0.0$ & $1.4 \pm 0.1$ \\
\hline Total $\omega-3$ PUFA & $2.2 \pm 0.5$ & $3.7 \pm 0.3$ & $5.2 \pm 1.0^{\S}$ \\
\hline \multicolumn{4}{|l|}{ diacyl-Phosphatidylcholine } \\
\hline Arachidonic acid & $2.7 \pm 0.3$ & $1.5 \pm 0.1^{1}$ & $1.6 \pm 0.1^{1}$ \\
\hline Total $\omega-6$ PUFA & $16.7 \pm 1.1$ & $13.9 \pm 1.1$ & $14.9 \pm 0.9$ \\
\hline Eicosapentaenoic acid & $0.1 \pm 0.0$ & $0.8 \pm 0.1^{* *}$ & $0.9 \pm 0.2^{* *}$ \\
\hline Docosahexaenoic acid & $0.4 \pm 0.1$ & $0.3 \pm 0.0$ & $0.7 \pm 0.2$ \\
\hline Total $\omega-3$ PUFA & $0.9 \pm 0.2$ & $1.6 \pm 0.1^{\ddagger}$ & $2.2 \pm 0.4^{\| \prime}$ \\
\hline \multicolumn{4}{|c|}{ alkylacyl-Phosphatidylcholine } \\
\hline Arachidonic acid & $13.1 \pm 0.7$ & $9.2 \pm 0.5^{* *}$ & $8.4 \pm 0.7^{* *}$ \\
\hline Total $\omega-6$ PUFA & $41.3 \pm 1.6$ & $35.6 \pm 1.1^{8}$ & $33.9 \pm 1.5^{\S}$ \\
\hline Eicosapentaenoic acid & $0.4 \pm 0.1$ & $4.8 \pm 0.4^{* *}$ & $8.4 \pm 0.7^{* *}$ \\
\hline Docosahexaenoic acid & $1.7 \pm 0.2$ & $1.6 \pm 0.1$ & $2.7 \pm 0.5$ \\
\hline Total $\omega-3$ PUFA & $3.6 \pm 0.4$ & $10.6 \pm 0.7^{* *}$ & $12.3 \pm 0.8^{* *}$ \\
\hline \multicolumn{4}{|c|}{ diacyl-Phosphatidylethanolamine } \\
\hline Arachidonic acid & $8.3 \pm 1.1$ & $4.0 \pm 0.3^{8}$ & $5.2 \pm 0.6^{\S}$ \\
\hline Total $\omega-6$ PUFA & $20.6 \pm 2.3$ & $12.6 \pm 0.5^{\S}$ & $14.3 \pm 0.7^{\ddagger}$ \\
\hline Eicosapentaenoic acid & $0.1 \pm 0.0$ & $1.0 \pm 0.1^{* *}$ & $1.5 \pm 0.1^{* *}$ \\
\hline Docosahexaenoic acid & $0.8 \pm 0.1$ & $0.5 \pm 0.1$ & $1.2 \pm 0.2$ \\
\hline Total $\omega-3$ PUFA & $1.6 \pm 0.3$ & $2.8 \pm 0.2^{\S}$ & $4.4 \pm 0.4^{* *}$ \\
\hline \multicolumn{4}{|c|}{ alk-1-enylacyl-Phosphatidylethanolamine } \\
\hline Arachidonic acid & $30.2 \pm 1.6$ & $18.4 \pm 0.9^{* *}$ & $19.8 \pm 1.0^{* *}$ \\
\hline Total $\omega-6$ PUFA & $54.0 \pm 1.9$ & $37.0 \pm 0.7^{* *}$ & $39.6 \pm 1.5^{* *}$ \\
\hline Eicosapentaenoic acid & $0.9 \pm 0.1$ & $10.4 \pm 0.6^{* *}$ & $9.6 \pm 0.8^{* *}$ \\
\hline Docosahexaenoic acid & $2.7 \pm 0.2$ & $3.1 \pm 0.2$ & $3.7 \pm 0.4^{*}$ \\
\hline Total $\omega-3$ PUFA & $9.3 \pm 1.3$ & $24.5 \pm 1.1^{* *}$ & $22.4 \pm 1.5^{* *}$ \\
\hline
\end{tabular}

${ }^{*} P<0.05$. ${ }^{\ddagger} P<0.01$. ${ }^{8} P<0.005$. " $P<0.001$. ' $P<0.0005$. ${ }^{* *} P<0.0001$.

cantly affected by dietary supplementation with $\omega-3$ PUFA. The binding of PAF to neutrophils was fitted by the Ligand program to a one-site model; the specific activity of $\left[{ }^{3} \mathrm{H}\right] \mathrm{PAF}$ used in this study was insufficient to assess the high affinity receptor. The dietary supplementation did not significantly affect the density or the affinity of the PAF receptors on neutrophils.

Neutrophil phosphoinositide formation. In the prediet period, levels of $\mathrm{IP}_{3}$ in $\mathrm{LTB}_{4}$ - and PAF-stimulated neutrophils were 3.2- and 5-fold higher than in the buffer-treated neutrophils $(P=0.012$ and 0.0004 , respectively, $n=8)$. In Fig. 1 , the suppression at 3 and 10 wk of dietary supplementation with $\omega-3$ fatty acids of phosphoinositide formation in neutrophils stimulated with $\mathrm{LTB}_{4}$ in a representative subject is shown in relation to the baseline. The net formation (buffer-control levels subtracted ) of $\mathrm{IP}_{3}$ in neutrophils stimulated by $\mathrm{LTB}_{4}$ for $15 \mathrm{~s}$ decreased by $71 \%$ after 3 wk of dietary supplementation $(0.033 \pm 0.013 \%, P=0.025)$ and by $90 \%$ after 10 wk of dietary supplementation $(0.011 \pm 0.011 \%, P=0.015)$ from prediet values $(0.114 \pm 0.030 \%$ ) (Fig. $2 A)$. Similarly, net formation of $\mathrm{IP}_{3}$ by PAF-stimulated neutrophils decreased by $62 \%$ after 3 wk $(0.074 \pm 0.029 \%, P=0.005)$ and by $96 \%$ after 10 wk $(0.008 \pm 0.005 \%, P=0.0004)$ from prediet values $(0.194 \pm 0.038 \%)$
(Fig. $2 B$ ). Comparable, statistically significant decreases were observed in the net formation of $\mathrm{IP}_{1}$ and $\mathrm{IP}_{2}$ by $\mathrm{LTB}_{4}$-stimulated neutrophils $\left(\mathrm{IP}_{1}: 76 \%, P=0.012\right.$, week 3 and $100 \%, P$ $=0.01$, week $10 ; \mathrm{IP}_{2}: 65 \%, P=0.0046$, week 3 and $100 \%, P$ $=0.0005$, week 10) and for PAF-stimulated neutrophils ( IP $_{1}$ : $71 \%, P=0.0052$, week 3 and $75 \%, P=0.0052$, week $10 ; \mathrm{IP}_{2}$ : $82 \%, P=0.012$, week 3 and $95 \%, P=0.0098$, week 10). Although $\mathrm{LTB}_{4}$ - and PAF-stimulated net $\mathrm{IP}_{3}$ formation correlated positively and significantly with the AA contents of the alkylacylPC and alkenylacylPE pools, generally, $\mathrm{LTB}_{4^{-}}$and PAF-stimulated $\mathrm{IP}_{3}$ formation correlated negatively but much better with the EPA contents of each of the major phospholipid subclasses in the neutrophil $(P=0.0005-0.0076)$ as evaluated for each subject at each time point. Despite the minimal EPA contents of the PI pool ( $\sim 2$ mol\%), LTB $_{4}$-stimulated net IP $_{3}$ formation correlated negatively and most strongly with the EPA content of the PI pool $(P=0.0005)$. PAF-stimulated $\mathrm{IP}_{3}$ formation also correlated strongly and negatively with the EPA content of the PI pool $(P=0.0012)$.

Neutrophil diacylglycerol formation. In the prediet period, the stimulation of neutrophils with $1 \mu \mathrm{M} \mathrm{LTB}{ }_{4}$ or $1 \mu \mathrm{M}$ PAF for $2 \mathrm{~min}$ in the presence of cytochalasin $\mathrm{B}$ resulted in significant increases in diglyceride formation above buffer control 


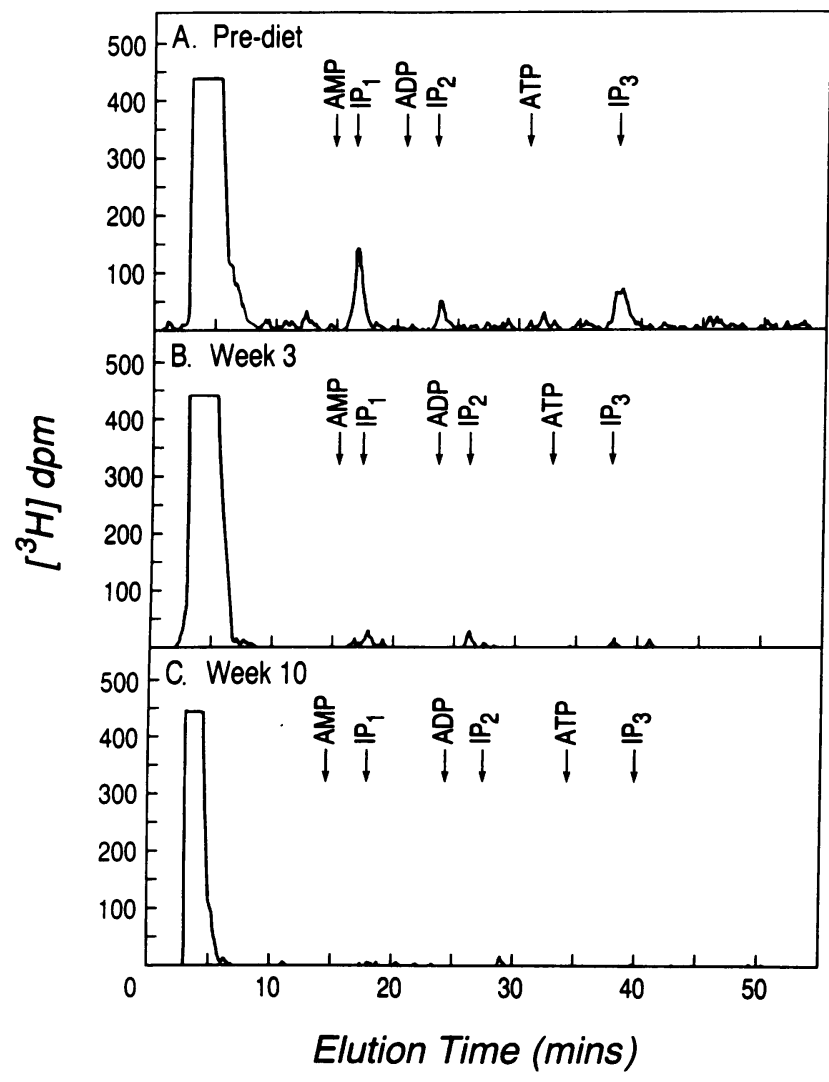

Figure 1. The inositol phosphates released by $\mathrm{LTB}_{4}$-stimulated neutrophils. The chromatograms from one study subject in the prediet period $(A)$ and after 3 wk $(B)$ and 10 wk $(C)$ of dietary supplementation with $\omega-3$ PUFA. Neutrophils were labeled with $\left[{ }^{3} \mathrm{H}\right]$ myoinositol and stimulated with $1 \mu \mathrm{M} \mathrm{LTB} 4$. Inositol monophosphate $\left(\mathrm{IP}_{1}\right)$, inositol bisphosphate $\left(\mathrm{IP}_{2}\right)$, and inositol trisphosphate $\left(\mathrm{IP}_{3}\right)$ were quantitated by on-line $\beta$-scintillation counting after resolution on anion-exchange HPLC. Data are expressed as dpm. levels (data not shown). Dietary supplementation with $\omega-3$ PUFA did not induce statistically significant changes in $\mathrm{LTB}_{4}$ and PAF-stimulated net diglyceride formation (data not shown) under conditions where most of the diglyceride derives from the phospholipase D pathway $(32,33)$.

Neutrophil chemotaxis. In the prediet period neutrophil chemotactic responsiveness both to $\mathrm{LTB}_{4}$ and to PAF increased with increasing concentrations $\left(10^{-9}-10^{-6} \mathrm{M}\right)$ of synthetic $\mathrm{LTB}_{4}$ and PAF as assessed in Boyden microchambers (Fig. 3). Dietary supplementation with $\omega$-3 PUFA significantly lowered the neutrophil chemotactic dose-response curve to $\mathrm{LTB}_{4}$ anf PAF; significant decreases were observed $3 \mathrm{wk}$ after the dietary supplement $\left(P=0.0016\right.$ for $\mathrm{LTB}_{4}, P=0.019$ for PAF) as compared with the baseline chemotactic dose-response curves. Further lowering of the neutrophil chemotactic dose-response curves to $\mathrm{LTB}_{4}$ and PAF was observed after 10 wk of dietary supplementation as compared with the week 3 ( $P$ $\leq 0.0001$ for $\mathrm{LTB}_{4}$ and $P=0.0018$ for PAF) and prediet periods ( $P \leq 0.0001$ for both $\mathrm{LTB}_{4}$ and PAF). The mean of the neutrophil chemotactic responses to $\mathrm{LTB}_{4}$ at the most effective concentration over the entire dose-response curve for each subject (mean maximal response) decreased by $69 \%$ after 3 wk ( $113 \pm 19$ cells $/ 5$ hpf, $P=0.0034$ ) and by $93 \%$ after 10 wk of dietary supplementation ( $26 \pm 5$ cells $/ 5$ hpf, $P \leq 0.0001$ ), as compared with the prediet period ( $361 \pm 78$ cells $/ 5 \mathrm{hpf})$. Similarly, the mean maximal response to PAF was decreased by $64 \%$ after 3 wk ( $130 \pm 33$ cells $/ 5$ hpf, $P=0.0033)$ and by $92 \%$ after 10 wk of dietary supplementation $(28 \pm 5$ cells $/ 5$ hpf, $P$ $\leq 0.0001$ ), as compared with the prediet period ( $358 \pm 89$ cells / $5 \mathrm{hpf}$ ). Neutrophil chemotaxis to both agonists correlated well with the AA contents of the alkylacylPC and alkenylacylPE pools, and it correlated highly and negatively with the EPA contents of each of the major phospholipid pools $(P=0.0009$ 0.0001 for $\mathrm{LTB}_{4} ; P=0.0067-0.0005$ for PAF). Although the EPA content of the PI pool was affected minimally ( $<2 \mathrm{~mol} \%)$ but significantly $(P \leq 0.0001)$ by the dietary supplementation
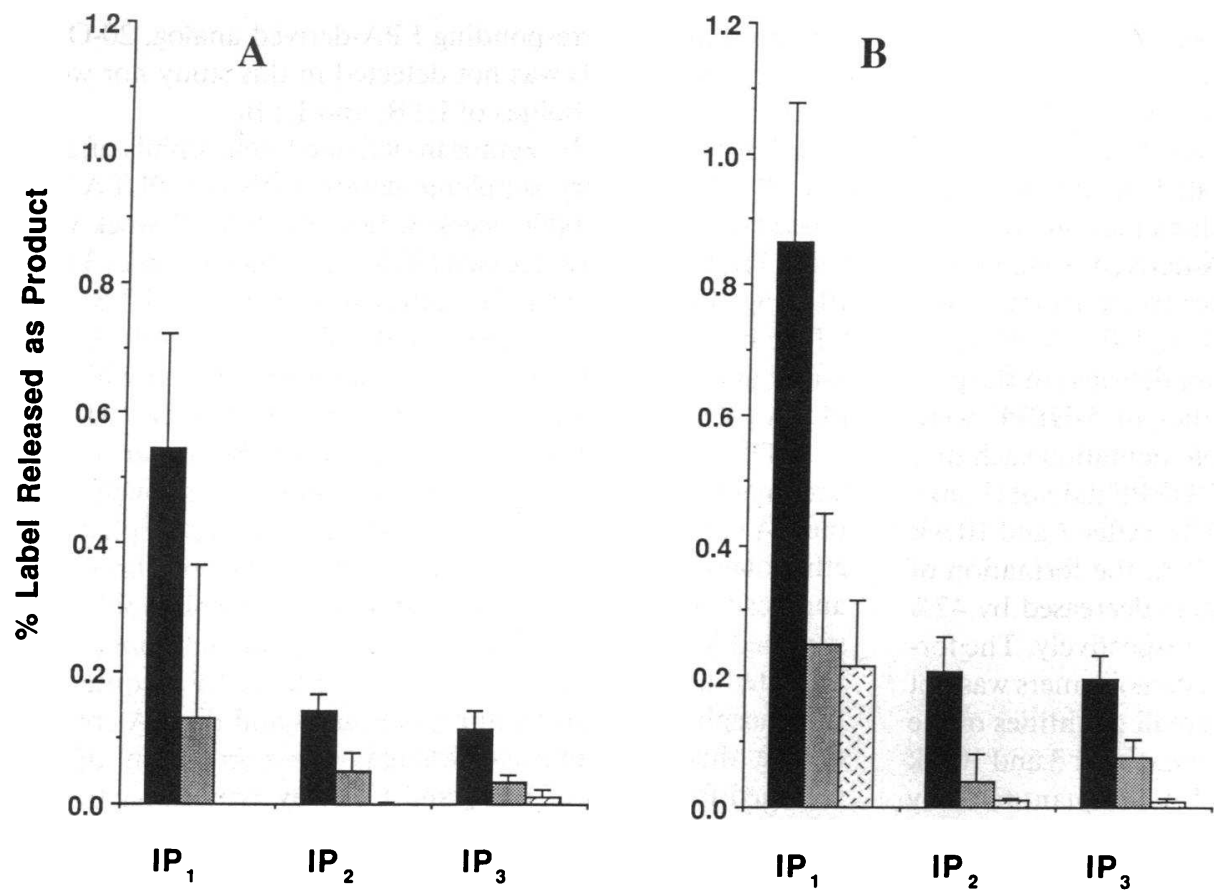

Figure 2. The effects of dietary $\omega-3$ PUFA on the release of inositol phosphates from neutrophils. Net percent release of $\left[{ }^{3} \mathrm{H}\right]$ as $\mathrm{IP}_{1}, \mathrm{IP}_{2}$, and $\mathrm{IP}_{3}$ in the prediet period (black bars) and after 3 (gray bars) and 10 wk (patterned bars) of dietary supplementation with $\omega-3$ PUFA as quantitated by on-line $\beta$-scintillation counting after resolution on anion-exchange HPLC. $(A)$ $\mathrm{LTB}_{4}$-stimulated neutrophils. $(B)$ PAF-stimulated neutrophils. Data are expressed as net percent release, mean \pm SEM, $n=8$, minus buffer control levels. 


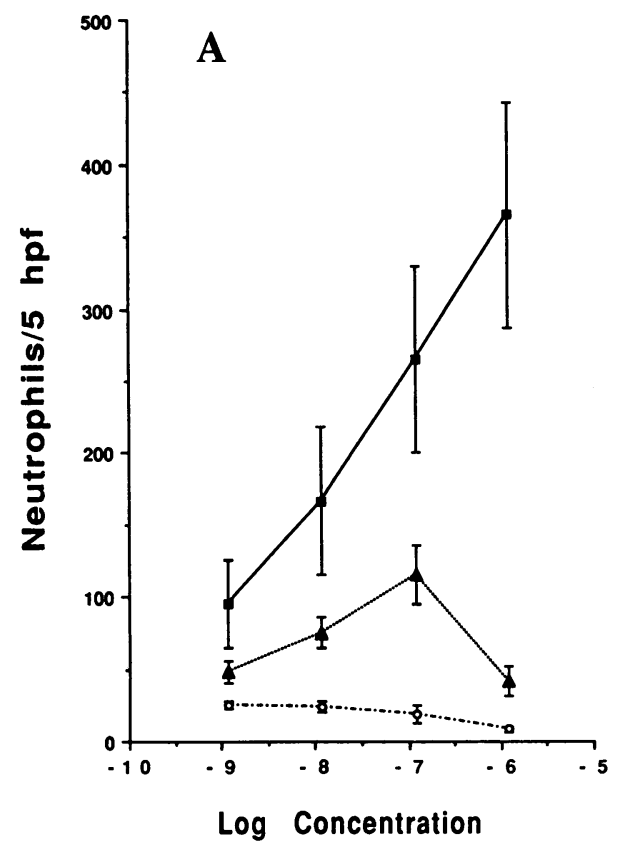

with $\omega$-3 PUFA, the negative correlation of neutrophil chemotaxis to both $\mathrm{LTB}_{4}$ and PAF with the EPA content of the PI pool in neutrophils was highly significant $\left(\mathrm{LTB}_{4}, P=0.0003\right.$; PAF, $P=0.0013$ ). Furthermore, the mean maximal chemotactic response to $\mathrm{LTB}_{4}$ after dietary supplementation with $\omega-3$ PUFA correlated strongly with $\mathrm{IP}_{3}$ formation by $\mathrm{LTB}_{4}$-stimulated neutrophils ( $P \leq 0.0001)$. Likewise, the mean maximal chemotactic response to PAF correlated strongly with $\mathrm{IP}_{3}$ formation by PAF-stimulated neutrophils $(P=0.0032)$.

Monocyte phosphoinositide and diglyceride formation. The net formation of total phosphoinositides in PAF-stimulated monocytes decreased modestly but did not reach statistical significance $(P=0.19)$, reflecting the absence of significant decreases in the net formation of $\mathrm{IP}_{1}, \mathrm{IP}_{2}$, and $\mathrm{IP}_{3}(P>0.2$ for each ). Similarly, the net formation of diglyceride in PAF-stimulated monocytes was not significantly affected by dietary supplementation with $\omega-3$ PUFA $(P>0.2)$.

Formation of 5-lipoxygenase pathway products by neutrophils. The formation of AA-derived 5-lipoxygenase pathway products by calcium ionophore-activated neutrophils decreased substantially after dietary supplementation with $\omega-3$ PUFA (Fig. $4 \mathrm{~A}$ ). The formation of AA-derived 5-HETE decreased by $44 \%$ after 3 wk and by $65 \%$ after 10 wk of dietary $\omega-3$ fatty acid supplementation $(P=0.0034$, and $P=0.0004$, respectively). EPA-derived 5-HEPE was not detected in the prediet period, whereas substantial quantities of 5-HEPE were formed after 3 and 10 wk of dietary supplementation such that the summed quantities of 5-HETE and 5-HEPE did not change appreciably over this time period $(P>0.2)$. After 3 and $10 \mathrm{wk}$ of dietary supplementation with $\omega-3$ PUFA, the formation of AA-derived 6-trans- $\mathrm{LTB}_{4}$ diastereoisomers decreased by $42 \%$ $(P=0.0013)$ and by $57 \%(P=0.0002)$, respectively. The for-

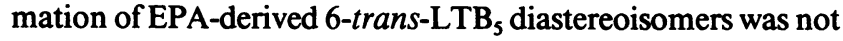
detected in the prediet period, whereas small quantities of the

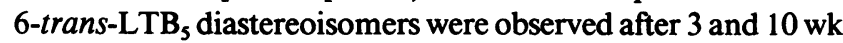
of dietary supplementation with $\omega-3$ PUFA. As quantitated by RIA, the formation of AA-derived $\mathrm{LTB}_{4}$ by calcium ionophore-activated neutrophils decreased by $71 \%$ after 3 wk $(P$
$=0.0061)$ of dietary supplementation and by $77 \%$ after $10 \mathrm{wk}$ $(P=0.0058)$ compared with the prediet period. RIA revealed the generation of small quantities of EPA-derived $\mathrm{LTB}_{5}$ in the prediet period; after dietary supplementation increased quantities of $\mathrm{LTB}_{5}$ were detected by both integrated optical density and RIA ( $256 \%, P=0.0008$, week $3 ; 205 \%, P=0.0022$, week 10; quantitated by RIA). The summed formation of $\mathrm{LTB}_{4}$ and LTB $_{5}$ decreased significantly and substantially after 3 and 10 wk of dietary supplementation (66\%), $P=0.0083$, week 3; $73 \%, P=0.0077$, week 10 ; quantitated by RIA), suggesting a selective action on the 5-lipoxygenase pathway at this step, catalyzed by the LTA epoxide hydrolase enzyme. The formation of 20-OH-LTB 4 , a metabolite of AA-derived $\mathrm{LTB}_{4}$, decreased by $46 \%$ after 3 and 10 wk of dietary supplementation with $\omega-3$ PUFA ( $P=0.017$ for each) relative to the prediet period; the formation of the corresponding EPA-derived analog, 20-OH$\mathrm{LTB}_{5}$, by neutrophils was not detected in this study nor were the 20-carboxy metabolites of $\mathrm{LTB}_{4}$ and $\mathrm{LTB}_{5}$.

$\mathrm{LTB}_{4}$ formation by zymosan-activated neutrophils after 3 and $10 \mathrm{wk}$ of dietary supplementation with $\omega-3$ PUFA decreased (61\%,P $=0.0006$, week $3 ; 58 \%, P=0.0007$, week 10 ), and $\mathrm{LTB}_{5}$ formation increased (325\%, $P=0.004$, weeks 3 and 10 ) (Fig. $4 B$ ). However, the summed formation of $\mathrm{LTB}_{4}$ and $\mathrm{LTB}_{5}$ by zymosan-activated neutrophils decreased signifcantly after 3 and 10 wk of dietary supplementation with $\omega-3$ PUFA ( $30 \%, P=0.02$, week $3 ; 28 \%, P=0.02$, week 10 ).

$\mathrm{LTB}_{4}$ formation in calcium ionophore-and zymosan-stimulated neutrophils correlated positively and most strongly with the AA contents of the phosphatidylcholine and phosphatidylethanolamine subclasses, and $\mathrm{LTB}_{5}$ formation correlated best and positively with the EPA content of the phospholipids. The summed formation of $\mathrm{LTB}_{4}$ and $\mathrm{LTB}_{5}$ by calcium ionophoreactivated neutrophils correlated best with the EPA content of the phosphatidylethanolamine subclasses and the AA content of the diacylPE subclass, whereas the correlation of the summed formation of $\mathrm{LTB}_{4}$ and $\mathrm{LTB}_{5}$ by zymosan-activated neutrophils with the fatty acid composition of the neutrophil phospholipid subclasses did not reach statistical significance. 

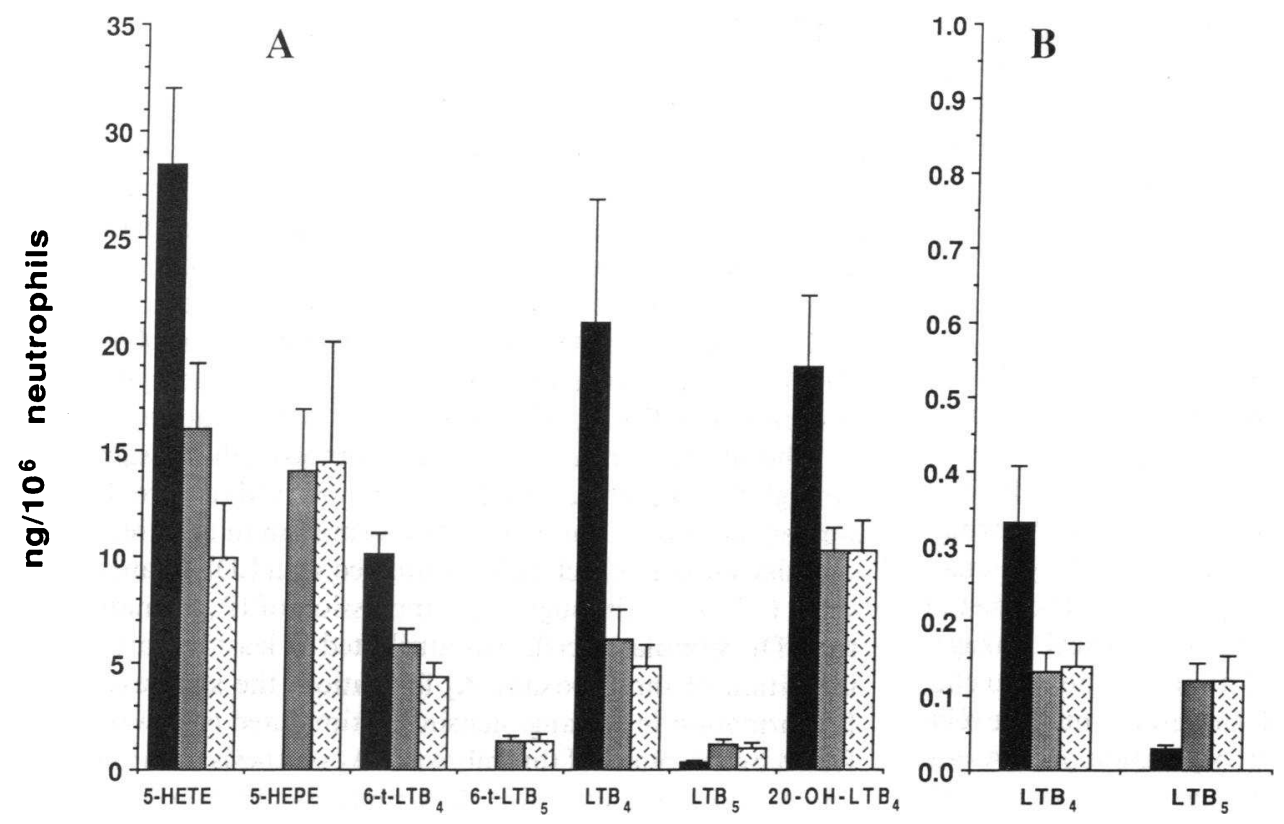

Figure 4. 5-Lipoxygenase pathway product generation by human neutrophils. $\mathrm{LTB}_{4}$ and $\mathrm{LTB}_{5}$ were quantitated by RIA after resolution on RP-HPLC, and the other 5-lipoxygenase products were quantitated by on-line integrated optical density after resolution on RPHPLC, in the prediet period (black bars) and after 3 (gray bars) and 10 wk (patterned bars) of dietary supplementation with $\omega-3$ PUFA. (A) Calcium ionophore A23187-activated neutrophils. $(B)$ Zymosan-stimulated neutrophils. Data are expressed as $\mathrm{ng} / 10^{6}$ neutrophils, mean \pm SEM, $n=8$.

Formation of 5-lipoxygenase pathway products by monocytes. The formation of AA-derived 5-lipoxygenase pathway products of monocytes decreased substantially after dietary supplementation with $\omega-3$ PUFA (Fig. $5 A$ ). The formation of 5-HETE by calcium ionophore-activated monocytes decreased by $65 \%$ after $3 \mathrm{wk}$ and by $47 \%$ after $10 \mathrm{wk}$ of dietary supplementation $(P=0.026$ and $P=0.048$, respectively). EPA-derived 5-HEPE was not detected in the prediet period, but substantial quantities of 5-HEPE were formed after 3 and 10 wk of dietary supplementation such that the summed quantities of 5-HETE and 5-HEPE did not change appreciably over this time period $(P>0.2)$. After 3 and $10 \mathrm{wk}$ of dietary supplementation with $\omega-3$ PUFA, apparent decreases in the formation of AA-derived 6-trans- $\mathrm{LTB}_{4}$ diastereoisomers were not statistically significant $(P=0.17)$. EPA-derived 6-trans- $\mathrm{LTB}_{5}$ diaste- reoisomers were not detected. The formation of $\mathrm{LTB}_{4}$ by calcium ionophore-activated monocytes decreased significantly after 3 and $10 \mathrm{wk}$ of dietary supplementation as compared with the prediet period ( $57 \%, P=0.0021$, week $3 ; 70 \%, P=0.0009$, week 10; quantitated by RIA). The generation of immunoreactive $\mathrm{LTB}_{5}$ increased after dietary supplementation with $\omega-3$ PUFA from the small quantities observed in the prediet period (432\%, $P=0.0007$, week $3 ; 295 \%, P=0.005$, week 10 ). Nevertheless, the summed formation of $\mathrm{LTB}_{4}$ and $\mathrm{LTB}_{5}$ by calcium ionophore-activated monocytes decreased significantly and substantially after 3 and 10 wk of dietary $\omega-3$ PUFA supplementation $(42 \%, P=0.025$, week $3 ; 58 \%, P=0.0093$, week 10 ; quantitated by RIA).

$\mathrm{LTB}_{4}$ formation by PAF-activated monocytes decreased after 3 and $10 \mathrm{wk}$ of dietary supplementation $(57 \%, P=0.013$,

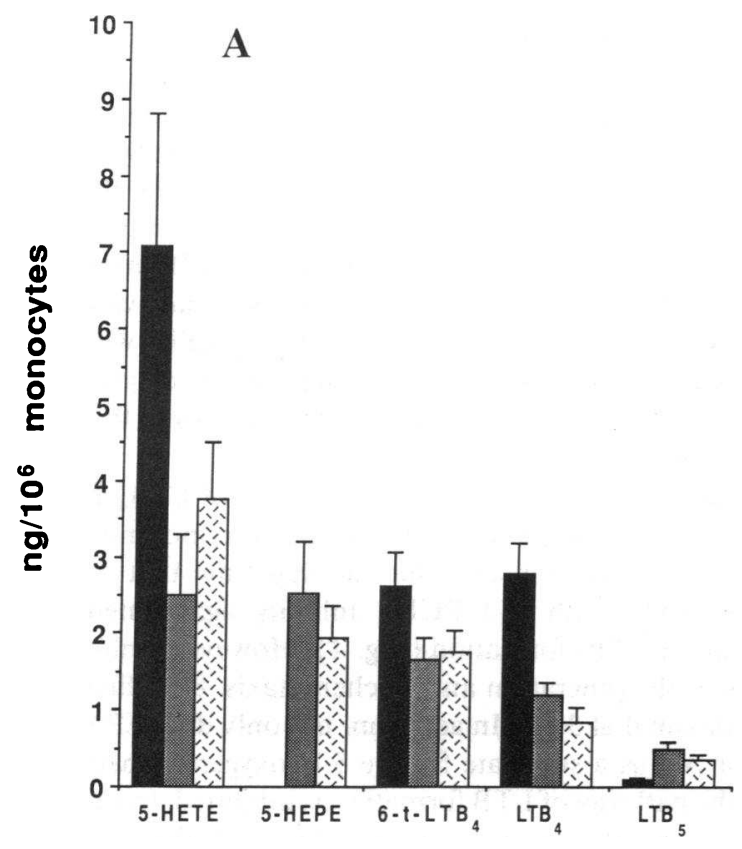

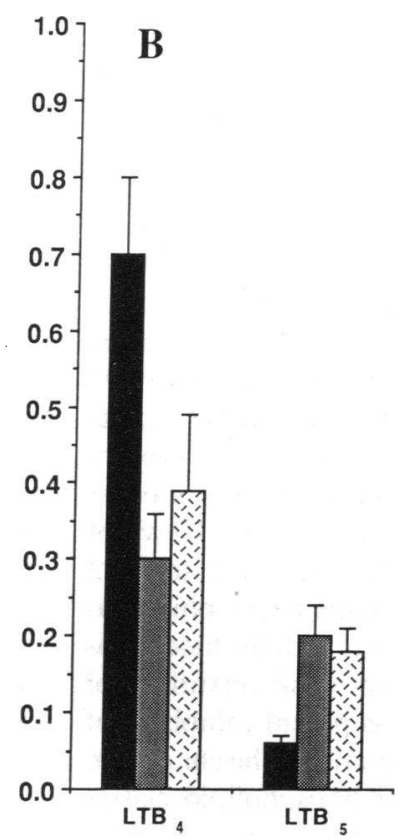

Figure 5. 5-Lipoxygenase pathway product generation by human monocyte monolayers. $\mathrm{LTB}_{4}$ and $\mathrm{LTB}_{5}$ were quantitated by RIA after resolution on RP-HPLC and the other 5-lipoxygenase products were quantitated by on-line integrated optical density after resolution on RP-HPLC, in the prediet period (black bars) and after 3 (gray bars) and 10 wk (patterned bars) of dietary supplementation with $\omega$-3 PUFA. ( $A$ ) Calcium ionophore A23187-activated monocytes. ( $B$ ) PAF-stimulated monocytes. Data are expressed as $\mathrm{ng} / 10^{6}$ monocytes, mean \pm SEM, $n=8$. 
week $3 ; 45 \%, P=0.022$, week 10 ) and $\mathrm{LTB}_{5}$ formation increased (265\%, $P=0.006$, week $3 ; 235 \%, P=0.0072$, week 10) (Fig. $5 B$ ). The decreases in the summed formation of LTB $_{4}$ and $\mathrm{LTB}_{5}$ by PAF-activated monocytes after 3 and 10 wk of dietary supplementation with $\omega-3$ PUFA (33\%, week 3; $24 \%$, week 10) approached but did not reach statistical significance $(P=0.20)$.

\section{Discussion}

This study of the effects of dietary enrichment with $\omega-3$ PUFA differs from previous studies in the parallel assessment of ligand-initiated signal transduction (inositol phosphates and diglycerides) and function (chemotaxis) in neutrophils. The profound suppression of $\mathrm{LTB}_{4}$ - and PAF-stimulated $\mathrm{IP}_{3}$ formation and chemotaxis in human neutrophils induced by dietary $\omega$-3 PUFA demonstrates a potentially significant role of diet in the modulation of cell signals. The tight statistical linkages among EPA incorporation into $\mathrm{PI}$ and $\mathrm{IP}_{3}$ production and chemotaxis in response to $\mathrm{LTB}_{4}$ and PAF suggest an intimate relationship in neutrophils between the incorporation of EPA into PI and the suppression of the biochemical and functional responses to the transmembrane signals. The absence of a statistically significant relationship between EPA incorporation into PI and the summed formation of $\mathrm{LTB}_{4}$ and $\mathrm{LTB}_{5}$ in response to either a particulate activator (zymosan) or the calcium ionophore indicates an independent, parallel action, through the formation of the EPA-derived intermediate LTA, which inactivates the LTA epoxide hydrolase (34). Together, the inhibition of $\mathrm{LTB}_{4}$ generation, the production of the functionally attenuated $\mathrm{LTB}_{5}$, and the suppression of the transduction of ligand-receptor signals negate the system of $\mathrm{LTB}_{4}$-mediated amplification of the neutrophil inflammatory response.

After 3 wk of high dose dietary supplementation with $\omega-3$ PUFA, neutrophil chemotaxis to $\mathrm{LTB}_{4}$ and PAF was dramatically inhibited (Fig. 3); mean maximal neutrophil chemotaxis to $\mathrm{LTB}_{4}$ and PAF was inhibited by 69 and $64 \%$, respectively; it was further suppressed after 10 wk of dietary supplementation. Perhaps because of the higher EPA and total $\omega-3$ PUFA dose used in this study, the magnitude of the inhibition of neutrophil chemotaxis was greater and appeared earlier than in previous studies $(9,11,12)$. The formation of $\mathrm{IP}_{3}$ in $\mathrm{LTB}_{4^{-}}$or PAF-stimulated neutrophils was nearly totally suppressed after dietary supplementation; the net formation of $\mathrm{IP}_{1}$ and $\mathrm{IP}_{2}$ was inhibited similarly (Figs. 1 and 2). The neutrophil chemotactic response to both $\mathrm{LTB}_{4}$ and PAF correlated strongly with the net $\mathrm{IP}_{3}$ formation by $\mathrm{LTB}_{4}$ - and PAF-stimulated neutrophils, suggesting a causal relationship between the suppression of $\mathrm{IP}_{3}$ formation and chemotaxis. The absence of a significant effect of the dietary $\omega-3$ PUFA supplementation on the densities or affinities of the respective receptors and the previous study (9) showing no change in membrane fluidity demonstrates a postreceptor inhibition of the $\mathrm{LTB}_{4}$ and PAF signals by the dietary supplementation with $\omega-3$ PUFA. Despite only very modest alterations in the PI pool in neutrophils after 3 and 10 wk of dietary supplementation (EPA content increased to $\sim 2$ mol\%), the EPA content of the PI pool of the neutrophils (Table 1) correlated significantly and negatively with the biochemical and functional responses. Thus even small quantities of EPA-containing species of PI may act as potent inhibitors of phospholipase $\mathrm{C}$, thus inhibiting $\mathrm{IP}_{3}$ formation. The changes in the fatty acid composition of the other phospholipid classes and subclasses may also contribute to the modulation of signal transduction and function in neutrophils. Dietary $\omega-3$ fatty acid supplementation did not substantially alter $\mathrm{LTB}_{4}$ - or PAFinduced net increments in neutrophil diglyceride levels. We interpret our data that dietary PUFA supplementation inhibited $\mathrm{IP}_{3}$ formation but did not appreciably affect diacylglycerol formation as consistent with the inhibition of a PI-selective phospholipase $\mathrm{C}$ and an absence of an effect on phospholipase $D$ by dietary supplementation with $\omega-3$ PUFA. The recent evidence that the major portion of the 1,2-diacylglycerol generated by stimulation of cytochalasin B-treated neutrophils with chemotactic agents is derived from PC by the activation of phospholipase $\mathrm{D}(32,33)$ supports this interpretation.

The alteration by $\omega-3$ PUFA of receptor-mediated signaling through the PI pathway has also been observed in vitro. In two studies, $\omega-3$ PUFA suppressed $\mathrm{IP}_{3}$ formation in cultures of rat vascular smooth muscle cells stimulated with LDL or angioten$\sin \mathrm{II}(35,36)$. Although this suppression of $\mathrm{IP}_{3}$ formation in the LDL-stimulated cells was attributed at least in part to the inhibition of thromboxane $A_{2}$ formation, the suppression of $\mathrm{IP}_{3}$ formation in the angiotensin II-stimulated cells was unaffected by inhibitors of thromboxane $A_{2}$ synthesis or thromboxane $A_{2}$ receptor antagonists. In vitro preincubation of aspirintreated rabbit platelets with EPA inhibits inositol phosphate formation (including $\mathrm{IP}_{3}$ formation) stimulated by the thromboxane $A_{2}$ receptor agonist, U46619 (37). Medini et al. (38) recently reported that dietary $\omega-3$ PUFA also inhibits thrombin-stimulated inositol phosphate formation by rabbit platelets without measurably affecting thromboxane formation. Weber et al. (39) have suggested that in vitro preincubation with DHA blunts the rise in intracellular calcium ion concentration in PAF- and $\mathrm{LTD}_{4}$-stimulated, retinoic acid-differentiated U937 cells through a noncyclooxygenase-mediated oxidation product of DHA. In the present study, such an effect of a DHA metabolite appears unlikely because it would need to occur early in the 15-s activation period to inhibit IP formation and because the only significant change in the content of DHA in neutrophil phospholipids was a minimal increase in the DHA content of alkenylacylPE only at $10 \mathrm{wk}$. As neutrophils are short lived ex vivo, only studies of dietary enrichment allow the achievement of a steady state necessary for the optimal interpretation of the neutrophil fatty acid composition data. Furthermore, in platelets, in which an in vitro steady state modulation of the fatty acid composition is possible, in vivo and in vitro studies yield different results (40), demonstrating the importance of the in vivo dietary studies. The current approach of dietary supplementation with $\omega-3$ PUFA has demonstrated for the first time a tight negative correlation between EPA incorporation into PI and agonist-induced formation of $\mathrm{IP}_{3}$ and chemotaxis. In the only other published study (37) that evaluated the fatty acid composition of cellular PI in parallel with the quantitation of inositol phosphate formation, the exposure to $\omega-3$ PUFA was in vitro, and no significant changes in the fatty acid composition of PI were observed.

The significant decreases in the formation of $\mathrm{LTB}_{4}$ and in the summed formation of $\mathrm{LTB}_{4}$ and $\mathrm{LTB}_{5}$ by zymosan-stimulated neutrophils demonstrate for the first time that dietary supplementation with $\omega-3$ PUFA inhibits ligand-mediated stimulation of $\mathrm{LTB}_{4}$ formation (Fig. 4). However, unlike the decreases in $\mathrm{IP}_{3}$ generation and in chemotaxis, this effect was already maximal at $3 \mathrm{wk}$. In addition, not only does EPA substitute for AA as a substrate for the 5-lipoxygenase pathway, but also the pathway of LTB formation is inhibited. In calcium ionophore-activated neutrophils, a selective inhibition of the 
summed formation of $\mathrm{LTB}_{4}$ plus $\mathrm{LTB}_{5}$, in parallel with a decrease in the $\omega$-oxidation products, was observed; the summed formation of 5-HETE plus 5-HEPE remained unchanged by dietary $\omega-3$ PUFA supplementation, suggesting inhibition of the LTA epoxide hydrolase. These results are in agreement with the findings of Terano et al. (11) and Hawthorne et al. (41) that dietary $\omega-3$ fatty acid supplementation causes selective inhibition of calcium ionophore-stimulated neutrophil LTB formation, whereas Lee et al. (9) found that dietary fish oil supplementation inhibited formation of all 5-lipoxygenase pathway products in ionophore-stimulated neutrophils. Nathaniel et al. (34) demonstrated that $\mathrm{LTA}_{5}$, derived from EPA, covalently binds to the LTA epoxide hydrolase and irreversibly inhibits the enzyme. The decreases in the formation of $\mathrm{LTB}_{4}$ and the summed formation of $\mathrm{LTB}_{4}$ and $\mathrm{LTB}_{5}$ in zymosanstimulated neutrophils were also significant.

In monocytes neither the decreases in PAF-stimulated levels of total phosphoinositides nor the changes in diglyceride formation after $\omega-3$ PUFA supplementation were significant. In the studies of Schmidt et al. (12) the inhibition by dietary $\omega-3$ PUFA supplementation of the chemotaxis in monocytes was less than that observed in neutrophils. In calcium ionophore-activated monocytes, a selective inhibition of $\mathrm{LTB}_{4}$ plus $\mathrm{LTB}_{5}$ formation was observed; the formation of 5-HETE plus 5-HEPE was unchanged by dietary supplementation with $\omega-3$ PUFA, again indicating inhibition of the epoxide hydrolase (Fig. 5). LTB formation by PAF-stimulated monocytes was also inhibited, but the degree of inhibition was less than that in calcium ionophore-activated monocytes.

The significant, tight correlation of the inhibition of chemotaxis and inositol phosphate formation with the EPA content of the neutrophil PI pool in the absence of a significant effect on neutrophil $\mathrm{LTB}_{4}$ and PAF receptor density or affinity and on diglyceride formation indicates that the inhibition of neutrophil chemotaxis to $\mathrm{LTB}_{4}$ and PAF by dietary $\omega-3$ PUFA supplementation is due to a selective postreceptor inhibition of the ligand-initiated signals via the PI-selective phospholipase C. The selective inhibition of the formation both of LTB and its metabolites in calcium ionophore-activated neutrophils and of LTB generation in zymosan-activated neutrophils plateaued at 3 wk and did not correlate with the incorporation of EPA into the PI pool. In contrast, the ligand-stimulated generation of $\mathrm{IP}_{3}$ and chemotaxis correlated negatively with the incorporation of EPA into the PI pool and was suppressed further after 10 wk of dietary supplementation. These differences are most consistent with an independent but parallel inhibition of the LTA epoxide hydrolase enzyme. Together, these data on ligand stimulation of human neutrophils reveal that incorporation of dietary EPA attenuates proinflammatory responses mediated by $\mathrm{LTB}_{4}$ by reducing the formation of this mediator, by substituting a functionally attenuated mediator $\left(\mathrm{LTB}_{5}\right)(42)$, and by inhibiting $\mathrm{LTB}_{4}$ receptor-mediated signal transduction as exemplified by the decreases in the formation of the inositol phosphates and in chemotaxis. The effects on cell signal transduction in the neutrophil were dramatic and reveal a novel and reversible (9) dietary-based approach to the modulation of ligand-initiated signaling via the phosphatidyl inositol pathway.

\section{Acknowledgments}

This research was supported in part by Grants AR-35907, AI-22531, AI-28465, AI-23401, AI-31599, and AR-38638 from the National Institutes of Health, Bethesda, MD, a postdoctoral research grant and a biomedical research center grant from the Arthritis Foundation, and research grants from the Lupus Foundation Association and the Davis Family Foundation.

\section{References}

1. Prickett, J. D., D. R. Robinson, and A. D. Steinberg. 1981. Dietary enrichment with the polyunsaturated fatty acid eicosapentaenoic acid prevents proteinuria and prolongs survival in NZBxNZW $F_{1}$ mice. J. Clin. Invest. 68:556-559.

2. Kelley, V. E., A. Ferretti, S. Izui, and T. B. Strom. 1985. A fish oil diet rich in eicosapentaenoic acid reduces cyclooxygenase metabolites, and suppresses lupus in MPL-lpr mice. J. Immunol. 134:1914-1919.

3. Leslie, C. A., W. A. Gonnerman, M. D. Ullman, K. C. Hayes, C. Franzblau, and E. S. Cathcart. 1985. Dietary fish oil modulates macrophage fatty acids and decreases arthritis susceptibility in mice. J. Exp. Med. 162:1336-1349.

4. Kremer, J. M., A. V. Michalek, L. Lininger, C. Huyck, J. Bigauoette, M. A. Timchalk, R. I. Rynes, J. Zieminski, and L. E. Bartholomew. 1985. Fish oil fatty acid supplementation in active rheumatoid arthritis. Lancet. 1:184-187.

5. Sperling, R. I., M. Weinblatt, J.-L. Robin, J. R. Ravalese III, B. W. Spur, D. R. Robinson, E. J. Corey, R. A. Lewis, and K. F. Austen. 1987. Effects of dietary supplementation with marine fish oil on leukocyte lipid mediator generation and function in rheumatoid arthritis. Arthritis Rheum. 30:988-997.

6. Kremer, J. M., W. Jubiz, A. Michalek, R. I. Rynes, L. E. Bartholomew, J. Bigaouette, M. Timchalk, D. Beeler, and L. Lininger. 1987. Fish-oil fatty acid supplementation in active rheumatoid arthritis: a double-blinded, controlled, crossover study. Ann. Intern. Med. 106:497-503.

7. Cleland, L. G., J. K. French, W. H. Betts, G. A. Murphy, and M. J. Elliott. Clinical and biochemical effects of dietary fish oil supplements in rheumatoid arthritis. 1988. J. Rheumatol. 15:1471-1475.

8. Kremer, J. M., D. A. Lawrence, W. Jubiz, R. DiGiacomo, R. Rynes, L. E. Bartholomew, and M. Sherman. 1990. Dietary fish oil and olive oil supplementation in patients with rheumatoid arthritis: clinical and immunologic effects. $A r$ thritis Rheum. 33:810-820.

9. Lee, T. H., R. L. Hoover, J. D. Williams, R. I. Sperling, J. R. Ravalese III, B. W. Spur, D. R. Robinson, E. J. Corey, R. A. Lewis, and K. F. Austen. 1985. Effect of dietary supplementation with eicosapentaenoic acid and docosahexaenoic acid on in vitro neutrophil and monocyte leukotriene generation and neutrophil function. N. Engl. J. Med. 312:1217-1223.

10. Hoover, R. L., M. J. Karnovsky, K. F. Austen, E. J. Corey, and R. A. Lewis. 1984. $\mathrm{LTB}_{4}$ action on endothelium mediates augmented neutrophil/endothelial adhesion. Proc. Natl. Acad. Sci. USA. 81:2191-2193.

11. Terano, T., A. Seya, A. Harai, H. Saito, Y. Tamura, and S. Yoshida. 1987. Effect of oral administration of highly purified EPA and DHA on eicosanoid formation and neutrophil function in healthy subjects. In Proceedings of the AOCS Short Course on: Polyunsaturated Fatty Acids and Eicosanoids. W. E. M. Lands, editor. American Oil Chemists' Society, Champaign, IL. 133-138.

12. Schmidt, E. B., J. O. Pedersen, S. Ekelund, N. Grunnet, C. Jersild, and J. Dyerberg. 1989. Cod liver oil inhibits neutrophil and monocyte chemotaxis in healthy males. Atherosclerosis. 77:53-57.

13. Bradford, P. G., and R. P. Rubin. 1985. Characterization of formylmeth ionyl-leucyl-phenylalanine stimulation of inositol trisphosphate accumulation in rabbit neutrophils. $M$ ol. Pharmacol. 27:74-78.

14. Omann, G. M., A. E. Traynor, A. L. Harris, and L. A. Sklar. 1987. LTB induced activation signals and responses in neutrophils are short-lived compared to formylpeptide. J. Immunol. 138:2626-2632.

15. Bradford, P. G., and R. P. Rubin. 1986. Quantitative changes in inositol 1,4,5-triphosphate in chemoattractant-stimulated neutrophils. J. Biol. Chem. 261:15644-15647.

16. Ganong, B. R., C. R. Loomis, Y. A. Hannun, and R. M. Bell. 1986 Specificity and mechanism of protein kinase $C$ activation by $s n$-1,2-diacylglycerols. Proc. Natl. Acad. Sci. USA. 83:1184-1188.

17. Böyum, A. Isolation of mononuclear cells and granulocytes from human blood. 1968. Scand. J. Clin. Lab. Invest., 21 (Suppl. 97):77-89.

18. Sperling, R. I., J.-L. Robin, K. A. Kylander, T. H. Lee, R. A. Lewis, and K. F. Austen. 1987. The effects of N-3 polyunsaturated fatty acids on the generation of PAF-acether by human monocytes. J. Immunol. 139:4186-4191.

19. Stenson, W. F., and C. W. Parker. 1979. Metabolism of arachidonic acid in ionophore-stimulated neutrophils: esterification of a hydroxylated metabolite into phospholipids. J. Clin. Invest. 64:1457-1465.

20. Corey, E. J., D. A. Clark, and A. Marfat. 1984. Structure elucidation and total synthesis of the leukotrienes. In The Leukotrienes: Chemistry and Biology. L. W. Chakrin, and D. C. Bailey, editors. Academic Press, New York. 14-101.

21. Falk, W., R. H. Goodwin, Jr., and E. J. Leonard. 1980. A 48-well chemotaxis assembly for rapid and accurate measurement of leukocyte migration. $J$. Immunol. Methods. 33:239-247.

22. Richards, K. L., and J. McCullough. 1984. A modified microchamber method for chemotaxis and chemokinesis. Immunol. Commun. 13:49-62.

23. Kreisle, R. A., and C. W. Parker. 1983. Specific binding of leukotriene $\mathbf{B}_{4}$ to a receptor on human polymorphonuclear leukocytes. J. Exp. Med. 157:628641. 
24. DiVirgilio, F., L. M. Vicentini, S. Treves, G. Riz, and T. Pozzan. 1985 Inositol phosphate formation in fMet-Leu-Phe-stimulated human neutrophils does not require an increase in the cytosolic free $\mathrm{Ca}^{2+}$ concentration. Biochem. J. 229:361-367.

25. Seiss, W. 1985. Evidence for the formation of inositol 4-monophosphate in stimulated human platelets. FEBS (Fed. Eur. Biochem. Soc.) Lett. 185:151156.

26. Irvine, R. F., E. E. Änggård, A. J. Letcher, and C. P. Downes. 1985. Metabolism of inositol 1,4,5-tris-phosphate and inositol 1,3,4-trisphosphate in rat parotid glands. Biochem. J. 229:505-511.

27. Preiss, J., C. R. Loomis, W. R. Bishop, R. Stein, J. E. Niedel, and R. M. Bell. 1986. Quantitative measurement of $s n$-1,2-diacylglycerols present in platelets, hepatocytes, and ras- and sis-transformed normal rat kidney cells. J. Biol. Chem. 261:8597-8600.

28. Folch, J., M. Lees, and G. H. Sloane Stanley. 1957. A simple method for the isolation and purification of total lipids from animal tissues. J. Biol. Chem. 226:497-505.

29. Patton, G. M., J. M. Fasulo, and S. J. Robins. 1982. Separation of phospholipids and individual molecular species of phospholipids by high performance liquid chromatography. J. Lipid Res. 23:190-196.

30. Blank, M. L., E. A. Cress, and F. Snyder. 1987. Separation and quantitation of phospholipid subclasses as their diradylglycerobenzoate derivatives by normal-phase high-performance liquid chromatography. J. Chromatogr. 392:421-425.

31. Ackman, R. G. 1987. Simplification of analyses of fatty acids in fish lipids and related lipid samples. Acta. Med. Scand. 222:99-103.

32. Billah, M. M., S. Eckel, T. J. Mullmann, R. W. Egan, and M. I. Siegel. 1989. Phosphatidylcholine hydrolysis by phospholipase $D$ determines phosphatidate and diglyceride levels in chemotactic peptide stimulated human neutrophils. J. Biol. Chem. 264:17069-17077.

33. Mullmann, T. J., M. I. Siegel, R. W. Egan, and M. M. Billah. 1990. Complement $\mathrm{C}_{5}$ activation of phospholipase $\mathrm{D}$ in human neutrophils: a major route to the production of phosphatidates and diglycerides. J. Immunol. 144:1901-1908.

34. Nathaniel, D. J., J. F. Evans, Y. Leblanc, C. Leveille, B. J. Fitzsimmons, and A. W. Ford-Hutchinson. 1985. LTA 5 is a substrate and an inhibitor of rat and human LTA, hydrolase. Biochem. Biophys. Res. Commun. 131:827-835.

35. Locher, R., E. Vogt, A. Steiner, and W. Vetter. 1988. The phosphoinositide turnover of vascular smooth muscle cells is influenced by fish oil. $J$. Hypertens. 6(Suppl 4):S222-S224.

36. Locher, R., A. Schinidis, A. Steiner, E. Vogt, and W. Vetter. 1989. Fish oil affects phosphoinositide turnover and thromboxane A metabolism in cultured vascular muscle cells. Biochim. Biophys. Acta. 1012:279-283.

37. Chetty, N., J. D. Vickers, R. L. Kinlough-Rathbone, M. A. Packham, and J. F. Mustard. 1989. Eicosapentaenoic acid interferes with U46619-stimulated formation of inositol phosphates in washed rabbit platelets. Thromb. Haemostasis. 64:1116-1120.

38. Medini, L., S. Colli, C. Mosconi, E. Tremoli, and C. Galli. 1990. Diets rich in n-9, n-6 and n-3 fatty acids differentially affect the generation of inositol phosphates and of thromboxane by stimulated platelets, in the rabbit. Biochem. Pharmacol. 39:129-133.

39. Weber, C., M. Aepfelbacher, I. Lux, B. Zimmer, and P. C. Weber. 1991. Docosahexaenoic acid inhibits PAF and $\mathrm{LTD}_{4}$ stimulated $\left[\mathrm{Ca}^{2+}\right]_{\mathrm{i}}$-increase in differentiated monocytic U937 cells. Biochim. Biophys. Acta. 1133:38-45.

40. von Schacky, C., W. Siess, S. Fischer, and P. C. Weber. 1985. A comparative study of eicosapentaenoic acid metabolism by human platelets in vivo and in vitro. J. Lipid Res. 26:457-464.

41. Hawthorne, A. B., B. L. Filipowicz, T. J. Edwards, and C. J. Hawkey. 1990. High dose eicosapentaenoic acid ethyl ester: effects on lipids and neutrophil leukotriene production in normal volunteers. Br. J. Clin. Pharmacol. 30:187194.

42. Lee, T. H., J.-M. Mencia-Huerta, C. Shih, E. J. Corey, R. A. Lewis, and K. F. Austen. 1984. Characterization and biologic properties of 5,12-dihydroxy derivatives of eicosapentaenoic acid, including leukotriene $B_{5}$ and the double lipoxygenase product. J. Biol. Chem. 259:2383-2389. 